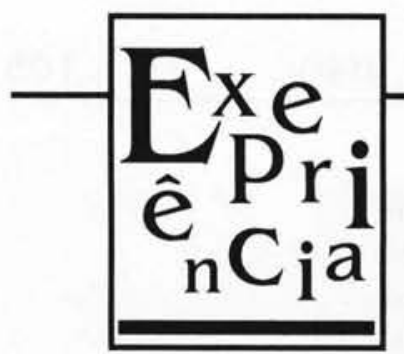

\title{
O JORNAL INFANTIL: CRITICAR E PRODUZIR
}

\author{
Relatando uma experiência com crianças do $1^{\circ}$ grau, de classes \\ sociais distintas, as autoras mostram o jornal infantil como \\ um instrumento de expressão, comunicação e inserção social, \\ revelando a criança como produtora de cultura.
}

Por que analisar o jornal infantil?

Em primeiro lugar, porque os suplementos infantis que circulam atualmente no mercado brasileiro necessitam de uma investigação mais cuidadosa, visto que, até o presente momento, poucos estudos se preocuparam em analisar este produto cultural. Depois, vem-se observando o uso crescente destes jornais em sala de aula como instrumento pedagógico, sem que haja, no entanto, uma reflexão mais elaborada sobre esta prática por

\section{AS AUTORAS}

Januária Cristina Alves

Mestre em Comunicação Social pela Escola de Comunicações e Artes da Universidade de São Paulo, jornalista e autora de Amor... Perdidos e Achados, livro infanto-juvenil da FTD Editora.

\section{Regina Mara Ramo}

Educadora Artística, especialista em Ação Cultural com Crianças e Jovens pela Escola de Comunicações e Artes da Universidade de São Paulo e técnica da Secretaria da Família e do Bem-Estar Social da Prefeitura Municipal de São Paulo. 
parte dos educadores. E, para encerrar, percebe-se que o projeto editorial dos suplementos infantis oscila entre o "didático" e o "lúdico", necessitando de uma maior proximidade com os anseios e necessidades do seu público leitor.

Para fundamentar estas observações de que o jornal infantil não atende aos interesses das crianças, optamos por trabalhar diretamente com elas, usando os suplementos infantis Folhinha de S. Paulo e O Estadinho que circulavam na cidade de São Paulo. Eram suplementos em formato tablóide, coloridos, encartados nos jornais Folha de S. Paulo e $\mathbf{O}$ Estado de S. Paulo aos domingos, compostos de 8 páginas (Folhinha) e 12 páginas (Estadinho), contendo anúncios, dicas de lazer e compras, passatempos, histórias em quadrinhos, contos, seção para correspondência com o suplemento e pequenas reportagens.

Para o início desse projeto, em outubro de 1987, escolhemos a metodologia da Leitura Crítica da Comunicação (LCC)' que, a partir de três perguntas simples - "do que você gostou", "do que você não gostou", "como você faria" -, estimula o espírito crítico das crianças. E elegemos dois grupos de crianças pertencentes a classes sócio-econômicas opostas.

Existe também a nossa preocupação, enquanto educadoras e agentes, em

desenvolver uma Ação Cultural com crianças nos moldes do "fazer com", possibilitando-lhes maneiras de participação e criação de um produto cultural que forneça meios para que reinventem a realidade,

colaborando, assim, para a formação de indivíduos críticos e capazes de desenvolver uma ação transformadora no meio em que vivem.

\section{OS GRUPOS}

O primeiro grupo de crianças com as quais trabalhamos entre outubro e novembro de 1987, freqüentava um Centro da Juventude chamado Nossa Senhora Aparecida - programa da Secretaria Municipal do Bem-Estar

1. O Projeto de Leitura Crítica da Comunicação (LCC) surge no final dos anos 70 e se consolida nos anos 80 como um trabalho coordenado de educação, voltado para a discussão da presença dos meios de comunicação na sociedade. Sob a liderança de Ismar de Oliveira Soares, Joana Puntel, José Manoel Morán, João Luís Van Tilburg, Pedro Gilberto Gomes, Attílio Hartmann, entre outros, um grupo de pesquisadores, professores de comunicação e agentes culturais desenvolvem, em São Paulo, um programa com referencial teórico e metodologia bem definidos, visando analisar, de forma dialética e participativa, o sistema de comunicação, a partir do lugar sócio-econômico e político dos receptores.

Os cursos de Leitura Crítica da Comunicação promovidos pelo projeto trabalham sistematicamente com produtos da indústria cultural (capítulos de novelas, artigos de jornais, programas de rádio, etc.) O método LCC trabalha com a imaginação e sobretudo com o pressuposto de que todos são produtores de cultura, dada a capacidade que todos temos de criar e recriar.

A entidade responsável pelo Projeto LCC é a UCBC - União Cristã Brasileira de Comunicação Social. 
Social da Prefeitura do Município de São Paulo, que atende, em convênio com Entidades Sociais, crianças de 7 a 14 anos e 11 meses, pertencentes à população de baixa renda (de 0 a 3 salários mínimos). Lá, elas recebiam alimentação e realizavam diversas atividades, no período de 4 horas (extraescolares). Esse primeiro grupo era composto de 21 meninos e meninas, que cursavam da segunda à quinta séries do primeiro grau de escolas públicas, na faixa etária de 9 a 13 anos.

O segundo grupo com o qual estivemos de abril a junho de 1988, freqüentava a quinta série do primeiro grau do Colégio São Luís, estabelecimento de ensino particular que recebe uma população de média/alta renda. Eram 22 crianças que tinham entre 10 a 11 anos, as quais, convidadas pela coordenação pedagógica, tinham manifestado interesse em produzir jornal.

\section{O PROCESSO}

Com cada um dos grupos tivemos em média dez encontros de uma hora cada, que se desenvolveram da seguinte forma:

12 Encontro: apresentação das educadoras; do grupo; colocação do motivo de estarmos ali (pesquisa para a faculdade), chamando a atenção de que cada criança deveria participar se quisesse; questionário objetivando levantar informações sobre o uso dos Meios de Comunicação de Massa (inclusive os próprios suplementos infantis) nas famílias às quais as crianças pertencem.

$2^{\circ}$ Encontro: apresentação da Folhinha ( $1^{\circ}$ grupo) e do Estadinho (os jornais foram comprados pelas próprias crianças). Após o contato empíricosensorial de cada criança com o seu exemplar, lançamos as 3 perguntas (LCC) que foram respondidas por escrito e também oralmente.

3- Encontro: cruzando as respostas escritas e orais do encontro anterior, colocadas em cartazes para melhor visualização, começamos a trabalhar a criticidade das crianças com relação ao produto exposto. Por exemplo: algumas gostavam de determinadas matérias, outras não. Através dessa constatação trabalhamos a diferença de opinião existente no grupo.

A contradição era percebida pelo grupo quando uma criança dizia não gostar de nada e especificava um item do qual tinha gostado.

Em seguida, utilizando o cartaz de um organograma mostrando as funções dos profissionais envolvidos na produção de um "grande jornal", explicávamos às crianças como ele funciona, como é dividido (cadernos, seções, etc.), confeccionado e distribuído. 
No $1^{\circ}$ grupo lançamos a proposta "vamos fazer um jornal?" - preparadas, se fosse o caso, para ouvir uma recusa por parte das crianças. Uma vez aceita a proposta, pedimos para que pensassem em como deveria ser um jornal feito por elas e para elas.

No $2^{\circ}$ grupo, já motivadas pela coordenação do colégio para a produção de um jornal, pedimos apenas que trouxessem suas sugestões no próximo encontro.

4 Encontro: colhemos as idéias das crianças para a produção do jornal. Cada criança escolheu sua função e tema (aquelas que queriam ser repórteres), de acordo com o que mais lhe agradava fazer.

5o Encontro: por votação oral, as crianças escolheram o nome do jornal, número de páginas, forma de distribuição, se seria gratuito ou pago, se manuscrito ou datilografado. Perguntamos também se alguém tinha mudado de idéia.

6ํㅡㄹ Encontro: a partir daí, acompanhamos o processo de confecção do jornal, levantamos as dificuldades do grupo, fizemos a votação das matérias que entrariam ou não no corpo do jornal e as crianças começaram a preparar a diagramação ( $1^{\circ}$ grupo).

$7^{\circ}$ Encontro: com o primeiro grupo o jornal já estava pronto para ser rodado. Com o segundo grupo, só nesse dia é que começaram a entregar suas matérias.

$8^{\circ}$ Encontro: com o primeiro grupo, fizemos a avaliação final que constou de: comparação do jornal deles com o da indústria cultural e comparação do produto com as idéias iniciais de como deveria ser o jornal deles, visualizando o cartaz do item "como faria". Nesse encontro, tivemos a presença do nosso orientador, Professor Doutor Ismar de Oliveira Soares, que por ser uma pessoa "de fora" do trabalho, realizou uma avaliação através de perguntas para as crianças.

Com o segundo grupo, fizemos nesse dia a votação e a leitura das matérias que entrariam ou não no jornal.

$9^{\circ}$ e $10^{\circ}$ Encontros: tentamos, com o segundo grupo, organizar o processo de feitura do jornal, porque estavam muito "perdidos". Colocamos a questão: "Querem desistir?". E eles negaram, querendo continuar.

11 Encontro: Visita com o segundo grupo ao jornal $\mathrm{O}$ Estado de $\mathrm{S}$. Paulo. Nesse dia o jornal ficou pronto para ser rodado.

$12^{\circ}$ Encontro: avaliação final do segundo grupo nos mesmos moldes do primeiro grupo.

O material utilizado para esse projeto foi muito simples: papel sulfite e lápis para as crianças escreverem, quadro negro, giz e folhas para os cartazes. 
Em todos os encontros, com os dois grupos, sentávamos em círculo para as discussões,

sendo nosso papel o de coordenar e organizar e nunca interferir dando respostas ou soluções, e sim deixando o grupo encontrá-las, descobri-las.

No primeiro grupo, por ser de crianças pertencentes a famílias de baixa renda, arcamos com as despesas para a confecção do jornal; no segundo, as crianças dividiram todas as despesas.

\section{TEMAS}

O que mais nos impressionou no momento em que os dois grupos criticaram a Folhinha e o Estadinho, é que estes jornais não correspondiam às suas expectativas. Foi geral a opinião de que seriam necessárias reportagens "mais interessantes", "passatempos mais inteligentes", "historinhas mais engraçadas" e "um visual diferente" (diagramação, fotos, cores, letras, etc., ...), como podem demonstrar as pautas por elas escolhidas:

1 Grupo: "Jornal das Crianças do C.J.A. (Centro da Juventude Nossa Senhora Aparecida)"

- Reportagens sobre OSEM (Orientação Sócio-Educativa ao Menor)

- Coordenadoras dos C.J.s

- A natureza não pode morrer

- Opiniões sobre crianças abandonadas

- Entrevista sobre AIDS

- Césio: conseqüências da contaminação

- Pão

- Unha de gato cura AIDS?

- Os meninos carreteiros

- Bazar de artesanato

- Espancamentos

- Horóscopo

- Pesquisa de opiniões

2 Grupo: "Gazeta do São Luís"

- MASP (Museu de Arte de São Paulo)

- Os vermelhinhos chegaram (os novos ônibus da CMTC)

- Quadrinhos

- Passatempos

- Exposição do MIS (Museu da Imagem e do Som)

- Entrevista com o coordenador da $5^{\mathrm{a}}$ série 
- Skate

- V Oliarque (Olimpíada do Colégio Arquidiocesano)

Com relação a essa temática,

ficou evidente a escolha de assuntos ligados ao universo adulto, como por exemplo AIDS, CÉSIO, HORÓSCOPO, MUSEUS e também temas atuais,

o que mostra que essas crianças não estão/são tão alienadas da realidade, como tenta mostrar a produção cultural para elas destinada. Dentro dessa escolha, as crianças de baixa renda mostraram, contudo, uma preocupação maior com temas sociais e polêmicos (conflitantes), numa tentativa de sensibilizar a sua comunidade (reportagens sobre crianças espancadas, crianças abandonadas), revelando uma aguda percepção dos problemas que lhes são mais próximos e evidentes. Já as crianças do segundo grupo se detiveram somente em assuntos que tratam do lazer e da "cultura" (no sentido mercadológico do termo), demonstrando uma desvinculação com o coletivo e uma supervalorização do individual, reproduzindo a ideologia da nossa sociedade capitalista.

$\mathrm{O}$ que se pode deduzir desse fato é que

as crianças do segundo grupo estão mais impregnadas do discurso homogeneizante, estratificante e "fragmentante" da escola, tal como se apresenta ainda hoje, espelho da sociedade,

não manifestando condições de, sozinhas, "recriarem" sua realidade. Quanto às crianças do primeiro grupo, mostraram-se capazes de criticar a situação na qual se encontram, desejando mudanças. Como exemplo, leiase o trecho a seguir tirado da reportagem Espancamentos de Lucineide (12 anos):

"Quando decidi fazer entrevistas sobre crianças espancadas eu pensei que seria fácil porque conheço muitas crianças que são espancadas, e muitas mães que costumam espancar os filhos (incluindo a minha). Mas, logo descobri que tinha escolhido uma missão praticamente impossível. A não ser por duas ou três exceções, todas as crianças que eu conheço e que sei que são espancadas, ou se negaram a responder à minha entrevista ou afirmaram que nunca foram espancadas na vida. Eu descobri que tanto a mãe que bate como a criança que apanha têm vergonha de confessar esse fato".

Comparemos com o seguinte trecho da reportagem Os vermelhinhos chegaram de Francisco (11 anos) do segundo grupo: 
"Estes ônibus novos, de marca MERCEDES BENZ têm acomodações confortáveis para o motorista, com um painel moderno, uma capa especial, para proteger os olhos dele num dos dias de grande sol paulista, e um vidro escuro que o separa do resto do ônibus. Se o ônibus é confortável para o motorista, também é para os passageiros: cadeiras almofadadas com muito espaço, podendo-se até estender as pernas, um piso bom, não escorregadio e até um papel de parede, que forra a parte interna do ônibus e em vez de um cordão para avisar ao motorista que você vai descer no próximo ponto, há um botão que, ao ser apertado, solta um barulho agradável".

\section{MEIOS DE COMUNICAÇÃO X CRIATIVIDADE}

Durante todo o trabalho foi visível a influência da televisão, do rádio e do jornal nos produtos elaborados pelas crianças.

Sempre que pensavam no assunto a ser escolhido para as reportagens, na postura enquanto "repórteres" ou mesmo na linguagem a ser utilizada, espelhavam-se nos Meios de Comunicação de Massa.

Podemos citar como exemplo o "Horóscopo" que apareceu no Jornal das Crianças do C.J.A., feito por Carlos e José Aparecido (12 anos), que disseram ter-se "inspirado" nos que as rádios AM costumam fazer todas as manhãs. Já as matérias sobre o MIS e o MASP da Gazeta do São Luís foram "inspiradas" nos moldes da revista Veja que costuma fazer esse tipo de abordagem no seu suplemento Veja São Paulo, que circula somente no estado de São Paulo. Na escolha dos temas para as reportagens, evidenciou-se também a transposição para os jornaizinhos das manchetes da TV na época (CÉSIO, AIDS, ÔNIBUS DA CMTC, etc.), inclusive procurando utilizar a mesma linguagem televisiva.

Os suplementos infantis influenciaram os produtos finais nas seções: "Passatempos" (praticamente iguais aos do Estadinho), "Quadrinhos" e na colocação de desenhos das crianças nos moldes da seção "O Espaço é Seu" da Folhinha.

Ambos os grupos fizeram questão de ter suas matérias datilografadas, corrigidas por um adulto (preocupação com o uso da norma padrão ensinada nas escolas), que o título do jornal (primeira página) fosse feito com letras de imprensa, que a diagramação fosse feita em colunas verticais, que houvesse fotos e/ou ilustrações perfeitamente distribuídas de acordo com o tema da reportagem e que o produto se aproximasse ao máximo das expectativas dos adultos do que deveria ser e conter um jornal "de verdade". 
Pode-se inferir, a esse respeito, que

os modelos apresentados pela escola e pelos Meios de Comunicação de Massa são passados de forma tão homogênea que as crianças os absorvem independentemente do meio no qual vivem e da classe econômica à qual pertencem.

Outro ponto em comum é o fato de que todas as crianças pareciam se perder na hora do "fazer", querendo encontrar o trabalho já finalizado, desejando "queimar etapas" e chegar logo ao jornal pronto (isso se evidenciou mais no segundo grupo devido à sua condição sócio-econômica), refletindo a incorporação do ritmo ágil da TV e do hábito adquirido na escola de encontrar os trabalhos praticamente prontos, como por exemplo, o trabalho com desenhos mimeografados que as crianças apenas têm que colorir.

Vale salientar que a faixa etária com a qual trabalhamos já está imbuída dos valores e crenças passados pela sociedade através da instituição escolar e da indústria cultural. A visão dicotômica (do "certo" e "errado") instaurou-se na sua ótica de mundo.

E o espírito crítico? Apesar de ser desestimulado pela escola e pelos Meios de Comunicação de Massa (que não estão preocupados com o "retorno" e nem com a recepção crítica por parte das crianças, interessando-lhes só o consumo passivo destes),

as crianças foram, sem dúvida, capazes de criticar e produzir um jornal infantil que retratou com clareza sua realidade,

diferenciando-se, nesse sentido, dos modelos existentes.

\section{LUGAR SOCIAL E VISÃO DE MUNDO}

A respeito da relação criança/visão de mundo, observamos as diferentes concepções que emergiram ao final deste trabalho. As crianças de nível sócio-econômico mais elevado, apesar de perceberem as injustiças existentes na nossa sociedade, não quiseram pensar e nem abordar esses assuntos no seu jornalzinho ("A classe social do São Luís é classe médialalta pra cima. Não se vivem conflitos, por isso não é necessário ter no jornal."; "As crianças não gostam desses assuntos."; "Conflito cansa."); enquanto que as de classe sócioeconômica inferior, além de perceberem mais claramente as contradições da estrutura social em que vivem, ainda tentaram produzir mudanças significativas em sua visão de mundo, não só criticando a indústria cultural, mas também elaborando um produto alternativo em seu conteúdo ("A matéria do Espancamento não é uma matéria feliz, fala de violência, mas a gente esperava fazer a cabeça das mães que batem nos filhos."). 
Acreditamos, assim, que

uma educação conscientizadora com relação aos Meios de Comunicação e à criatividade na emissão de mensagens, passa pela questão do lugar sócio-econômico em que se encontram as crianças.

\section{OPINIÃO: UMA FORMA DE EXPRESSÃO}

Durante todo o processo de feitura do jornal, as crianças tiveram a oportunidade de opinar sobre todos os assuntos que envolviam o produto. Por votação, elas escolheram o nome do jornal, selecionaram as matérias que entrariam ou não no corpo, quais as tarefas de cada uma, a forma de distribuição; enfim, nada foi definido sem a participação de cada membro dos grupos. Essa forma de organização gerou "surpresa" e insegurança para as crianças, fazendo com que elas tivessem dificuldade em exercer o ato de opinar, comportando-se desorganizadamente e demonstrando uma certa ansiedade em se colocar.

Esse fato só reforça a constatação

da visão que a sociedade atual tem da criança: um ser improdutivo, um "adulto em potencial", a quem não é dado o direito de produzir e muito menos de criticar,

só sendo permitido receber e aceitar passivamente aquilo que lhe é definido como adequado. $\mathrm{O}$ espanto das crianças, quando se defrontaram com a oportunidade de opinar e de serem ouvidas com seriedade, se deve ao fato de suas opiniões terem sido sempre encaradas, até ali, como algo "interessante", porém irrelevante.

\section{A CRIANÇA COMO PRODUTORA DE CULTURA}

Com este trabalho pensamos estar mostrando que a criança faz cultura, não uma cultura "produtiva" no sentido econômico, mas algo vivo, pulsante, que denota uma possibilidade de participação ativa no contexto social.

Mesmo não sendo reconhecidas como produtoras de cultura pelo adulto - que vê no consumo de bens culturais a única forma de a criança vir a ser um indivíduo "completo", um adulto evoluído -

a criança consegue, contudo, subverter essa idéia através do lúdico, criando a si própria e também a sua cultura.

Observando o processo vivido por elas e os produtos resultantes deste, constatamos que jornais como a Folhinha e o Estadinho subestimam a capacidade crítica delas enquanto receptoras e consumidoras desses suplementos. 
Trabalhos como o nosso podem não ter condições imediatas de transformar o mecanismo arraigado da indústria cultural. Nosso objetivo é, porém, contribuir para a formação de sujeitos que tenham condições de interferir nesse mecanismo, seja como produtores e/ou consumidores.

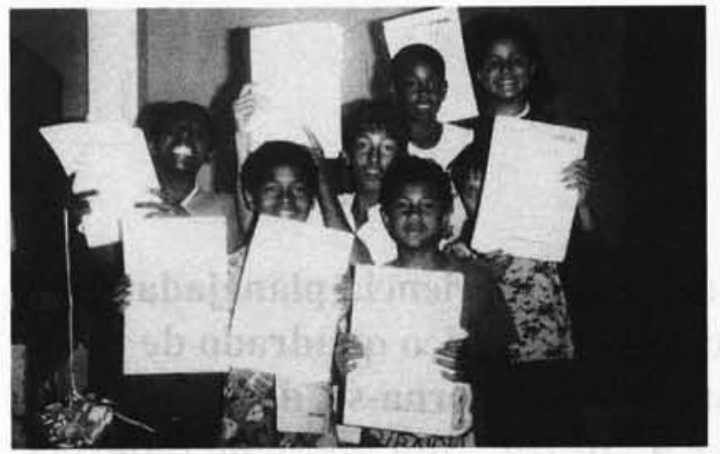

Crianças do C.J.A e capa do Jornal das Crianças do C.J.A" no dia em que finalizaram o jornalzinho.

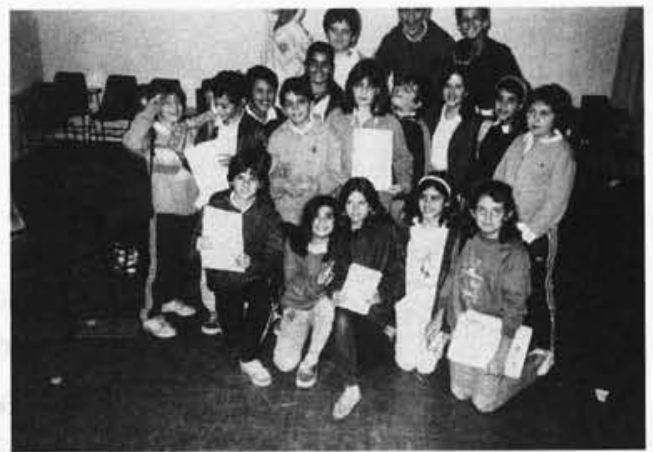

Alunos do Colégio São Luís com a "Gazeta do São Luís" no dia em que finalizaram o jornalzinho.
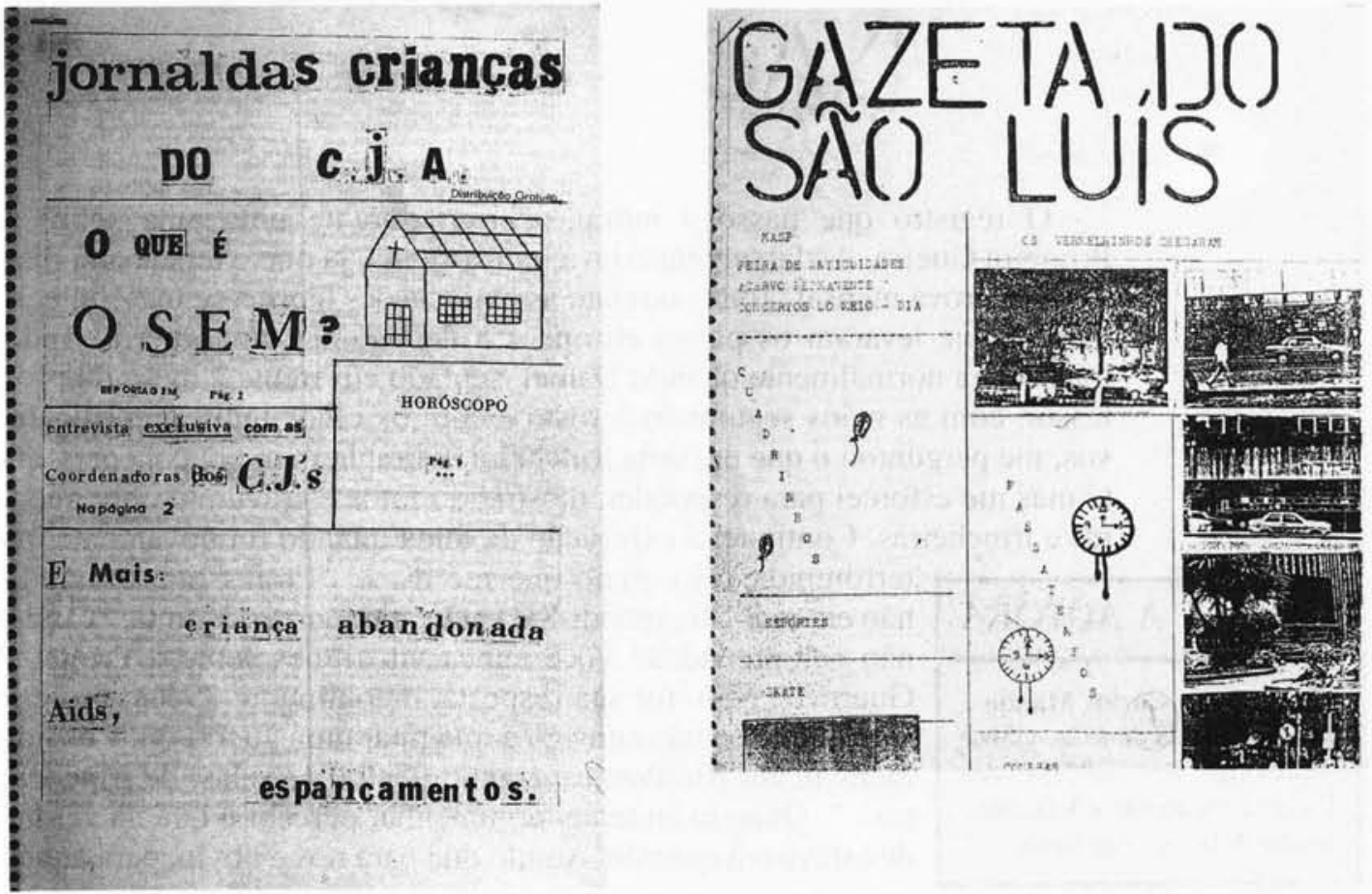